Altai State University

Acta Biwlogica Sibirica

Journal of Biology

Founded in 2015

\title{
The spatial scaling of impact in edaphic and plant factors on the structuring of the soil macrofauna community
}

\author{
Y.Y. Dubinina \\ Melitopol Institute of Ecology and Social Technologies of the Open International University of Human \\ Development "Ukraine", Interculturnaya st., 380, Melitopol, 72316, Ukraine.
}

\begin{abstract}
In this paper, the role of edaphic factors and plant, as well as the spatial variables was revealed in the structuring of the forest biogeocenosis soil macrofauna community in the river Dnepr arena within the nature reserve of "Dnepr-Orelsky" (Ukraine). 44 species of soil animals were found in the test polygon after manual sorting of soil samples. The density of the soil macrofauna in studied polygon is $321.5 \pm 43.2 \mathrm{ind} . / \mathrm{m}^{2}$. It is shown that the soil macrofauna community is structured under the influence of edaphic, plant and spatial factors. The role of these factors is different at fine-scale, medium-scale and broad-scale spatial levels. The variation of the community structure under the influence of edaphic and plant factors can be classified as deterministic processes, which is carried out within the framework of the ecological niche theory. The spatial component of the variation can be attributed to the result of the neutral nature of the factors. However, it should be noted that the spatial variation of plant community also is subject to the deterministic and neutral control. This manifests itself in the spatial structuring of plant factors. The spatial variation of soil properties has a similar nature. Soil as environment undergoes structuring influence of vegetation, where there are spatial patterns of soil properties. Scale effects of variation in space manifest themselves in different ways for the representatives of different ecological groups of macrofauna. For litter forms the most characteristic spatial patterns on large and medium-scale level, and for proper soil and burrowing forms - on fine-scale level.
\end{abstract}

Key words: Spatial variation, environmental factors, ecological niche, neutral variety, environmental groups

\section{Пространственная масштабность в воздействии эдафических и растительных факторов на структурирование сообщества почвенной макрофауны}

\author{
Ю.Ю. Дубинина
}

Мелитопольский институт экологии и социальных технологий открытого международного университета гуманитарного развития «Украина», ул. Интеркультурная, 380, г. Мелитополь, 72316, Украина, E-mail: dubinina4884@уа.ru

В работе установлена роль эдафических и растительных факторов, а также пространственных переменных в структурировании сообщества почвенной макрофауны лесного биогеоценоза на арене р. Днепр в пределах природного заповедника «Днепровско-Орельский» (Украина). В почве исследуемого полигона было при ручной разборке проб обнаружено 44 вида почвенных животных. Плотность почвенной макрофауны изученного

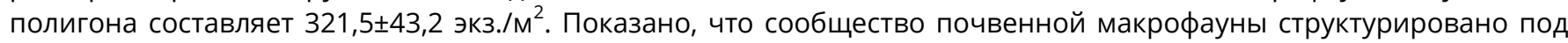
воздействием эдафических, растительных и пространственных факторов. Роль этих факторов различна на детальномасштабном, среднемасштабном и широкомасштабном пространственных уровнях. Варьирование структуры сообщества под влиянием эдафических и растительных факторов можно отнести к категории 
детерминистского воздействия, которое осуществляется в рамках теории экологической ниши. Пространственную компоненту варьирования можно отнести к результатам действия факторов нейтральной природы. Однако следует отметить, что пространственное варьирование растительного сообщества также подчиняется действию детерминистских и нейтральных факторов. Это проявляет себя в пространственной структурированности растительных факторов. Аналогичную природу имеет и пространственное варьирование почвенных свойств. Почва как среда обитание испытывает структурирующее влияние растительного покрова, откуда возникают пространственные паттерны почвенных свойств. Масштабные эффекты варьирования в пространстве проявляют себя по-разному для представителей различных экологических групп макрофауны. Для подстилочных форм в наибольшей степени характерны пространственные паттерны на крупно- и среднемасштабном уровне, а для собственно почвенных форм и норников - на детальномасштабном уровне.

Key words: Пространственное варьирование, экологические факторы, экологическая ниша, нейтральное разнообразие, экологические группы

\section{Введение}

Пространственные и экологические градиенты оказывают влияние на пространственную вариацию видового богатства и структуры сообщества (Lawton, 1999; Hubbell, 2001). Бета-разнообразие определено как изменчивость видового состава сообщества от места к месту (Whittaker, 1960, 1972; Legendre et al., 2005). Этот концепт играет ключевую роль в идентификации и понимании паттернов разнообразия на различных иерархических уровнях (Soinenen et al. 2007). Механизмы, управляющие бета-разнообразием, являются либо детерминистскими либо стохастическими процессами (Barot, Gignoux, 2004; Laliberte et al., 2009). Оценка роли каждого из этих факторов находит свое выражение в дебатах между теорией экологической ниши и теорией нейтрального разнообразия (Hutchinson, 1957; Hubbell, 2001; Adler et al., 2007; Clark, 2012). В соответствии с теорией экологической ниши два пространственно близкие локальные сообщества находятся под влиянием подобных условий окружающей среды, определяющих пространственные паттерны ресурсов и условий, что обуславливает пространственную автокорреляцию сообщества. В свою очередь теория нейтральности также предсказывает то, что с увеличением географического расстояния различия между сообществами будут также увеличиваться, т.е. нейтральная динамика также способна генерировать пространственную автокорреляцию (Caruso et al., 2012). Ключевое различие между детерминистской и нейтральной динамикой состоит в том, что последняя определяет пространственные паттерны независимо от изменений свойств окружающей среды (Hubbell, 2001; Chave, 2004; Dornelas et al., 2006). Разбиение переменных среды и пространственных дескрипторов, полученных на основании географических координат, на индивидуальные и комбинированные компоненты, а затем оценка, как эти переменные коррелируют с изменчивостью состава сообщества или его разнообразием (так называемое фракционирование вариации - Borcard et al., 1992; Legendre et al., 2009), позволяет выявить роль нейтральных и ниша-зависимых механизмов (Murphy et al., 2015). Если пространственная автокорреляция не может быть объяснена факторами среды, то она рассматривается как результат действия нейтральных механизмов, таких, как специфичное ограничение дисперсии (Legendre et al. 2009; Hu et al., 2013; Siefert et al. 2013). Следует отметить, что полное отнесение вариации, объясненной с помощью пространственных дескрипторов, к нейтральным механизмам не является оправданным, так как эта компонента не может быть отделена от неизмеренных пространственно структурированных переменных (Anderson et al., 2011). Taкже вариация, которая полностью отнесена только лишь к переменным среды, может случайно отражать паттерны, действительно возникающие вследствие нейтральных процессов (Murphy et al., 2015).

Экологические процессы определяются воздействиями на различных масштабных уровнях, которые находятся в диапазоне от локального до глобального (Legendre, 1993; Zhukov et al., 2013). В естественных сообществах наблюдаемые пространственные паттерны являются результатом действия факторов окружающей среды, определяются биологическими и/или историческими причинами (Dray et al., 2006). Действие этих причин не является взаимоисключающим, а скорее является комплементарным (Jiménez et al., 2014). Существование пространственных структур у комплексов видов предполагает действие, по меньшей мере, одного из структурирующих факторов. К их числу можно отнести пространственно распределенные факторы среды, которые структурируют сообщества в соответствии с теорией экологической ниши (Hutchinson, 1957, 1965). Также важно отметить, что на некоторых пространственных уровнях в структурировании группировок видов играют важную роль межвидовые взаимодействия (Schoener, 1974; Wilson, Habiba, 1995; Belyea, Lancaster, 1999; Zhukov, Gubanova, 2015). Межвидовые взаимодействия могут привести к двум противоположным типам динамики. Сильные взаимодействия могут сделать сообщество либо детерминистским, либо исторически обусловленным (Chase, 2003). Исторические обстоятельства в соответствии теорией нейтральности (Ellwood et al., 2009) или стохастические вариации в истории появления видов в сообществе (Drake, 1990, Weslien et al., 2011) могут оказать существенное влияние на сообщество. Однако идиосинкратичность исторических эффектов представляет значительное препятствие для предсказания динамики экосистемных функций (Fukami et al., 2010). Очень важно оценить вклады различных процессов, особенно с учетом того, что исторические процессы и история 
перемещения видов в данный момент времени не наблюдаемы (Fukami, 2010; jiménez et al., 2014). Решение этой проблемы может состоять в исследовании пространственных масштабов при которых имеет значение история формирования комплексов живых организмов. Было высказано предположение, что экологическая гетерогенность имеет наибольшее значение для структурирования комплексов на широком масштабном уровне, тогда как стохастические процессы, такие как дисперсия, действуют на более детальных масштабных уровнях (Legendre, 1993; Laliberte et al., 2009; Gazol, Ibanez, 2010).

В соответствии с детерминистской точкой зрения, условия окружающей среды определяют то, какой из видов регионального пула останется в сообществе в результате видовых взаимодействий. В этом случае история иммиграции не влияет на финальную композицию видов. Если же сообщество является исторически обусловленным, то условия среды не определяют единственное климаксовое сообщество (Fukami, 2010). Роль для сообщества таких пространственные характеристик, как размер пятен, где сообщество представлено, уровень их изоляции и пространственная гетерогенность, зависит от пространственного масштаба способности видов к перемещению (Cadotte, Fukami, 2005).

Геостатистика дает возможность оценить пространственное распределение изменчивости свойств среды и почвенных организмов (Rossi et al., 1996; Rossi et al., 2003). Однако для моделирования пространственных структур на различных масштабных уровнях необходимы другие статистические инструменты, к числу которых можно отнести анализ главных координат матриц соседства (principal coordinates of neighbor matrices - PCNM) (Dray et al. 2006, Borcard, Legendre, 1994; Borcard et al., 2004). Этот подход позволяет связать варьирование свойств среды со структурой сообщества на различных пространственных уровнях (Rossi et al., 1996; Borcard, Legendre, 1994).

Сообщества почвенных организмов структурированы в силу их ответа на пространственную изменчивость почвенных ресурсов (Drake, 1990; Blanchet et al., 2013; Decaëns et al., 2009; Jiménez et al., 2012). Пространственная гетерогенность создает условия для сосуществования конкурирующих видов (Jiménez et al., 2012; Amarasekare, 2003). Показано, что почвенные беспозвоночные формируют пространственные паттерны, которые изменяются в диапазоне от размеров отдельных агрегатов (Ettema, Yeates, 2003) до размеров отдельных растений (Rossi et al., 1996), сельскохозяйственных полей и естественных экосистем (Decaëns, Rossi, 2001; Rossi, 2003; Whalen, 2004). Отдельные виды различаются по степени агрегации (McArdle, Anderson, 2004), поэтому нейтральные процессы могут наблюдаться на различных масштабных уровнях для различных видов (Anderson et al., 2011).

Была оценена взаимосвязь свойств среды и сообществ дождевых червей с учетом многомасштабного взаимодействия (Jiménez et al., 2014). Показано, что отношения между пространственной организацией сообщества дождевых червей и почвенных свойств демонстрируют многоуровневый характер. Среди почвенных свойств, которые описывают вложенную структуру популяций в пределах многоуровневого градиента, выделена детально-масштабная (< 10 м) и средне-масштабная (10-20 м) компоненты. Почвенные свойства описывают 1-48 \% изменчивости пространственной вариации сообществ дождевых червей (Jiménez et al., 2014).

Важной проблемой является вопрос о природе экологических градиентов в почве как среде обитания живых организмов. Наряду с рельефом как фактором перераспределения климатических ресурсов, факторы фитогенной и зоогенной природы выступают как источники неоднородности свойств почвы (Karpachevsky, 2005). Влияние мезорельефа проявляется на крупномасштабном уровне, а фитогенные и зоогенные эффекты проявляются на крупномасштабном, так и на детальномасштабном и среднемасштабном уровнях (Zhukov et al., 2013). B свою очередь пространственные паттерны растительности или педотурбационной активности животных могут иметь нейтральную природу. Таким образом, нельзя исключать того, что факторы гетерогенности экологических свойств почвы в своей основе генерированы нейтральными причинами. Поэтому мы считаем актуальной проблемой оценку соотношения пространственных факторов, а также факторов эдафической и растительной природы в организации сообщества почвенной макрофауны.

Целью настоящего исследования является установить соотношение эдафических и растительных факторов, а также пространственных переменных в структурировании сообщества мезопедобионтов прирусловой поймы р. Днепр в пределах природного заповедника «Днепровско-Орельский».

\section{Материал и методы}

Исследования проведены в апреле-мае 2014г. в природном заповеднике «Днепровско-Орельский» (Украина). Исследуемый полигон заложен на участке, который находится в прирусловой пойме р. Днепр (48³0'6" С.Ш., 3447'18" В.Д.). Исследуемый полигон заложен на участке, который находится в зоне перехода арены р. Днепр в притеррасную пойму р. Проточь. Полигон состоит из 7 трансект. Каждая трансекта составлена из 15 пробными точками (рис. 1). 


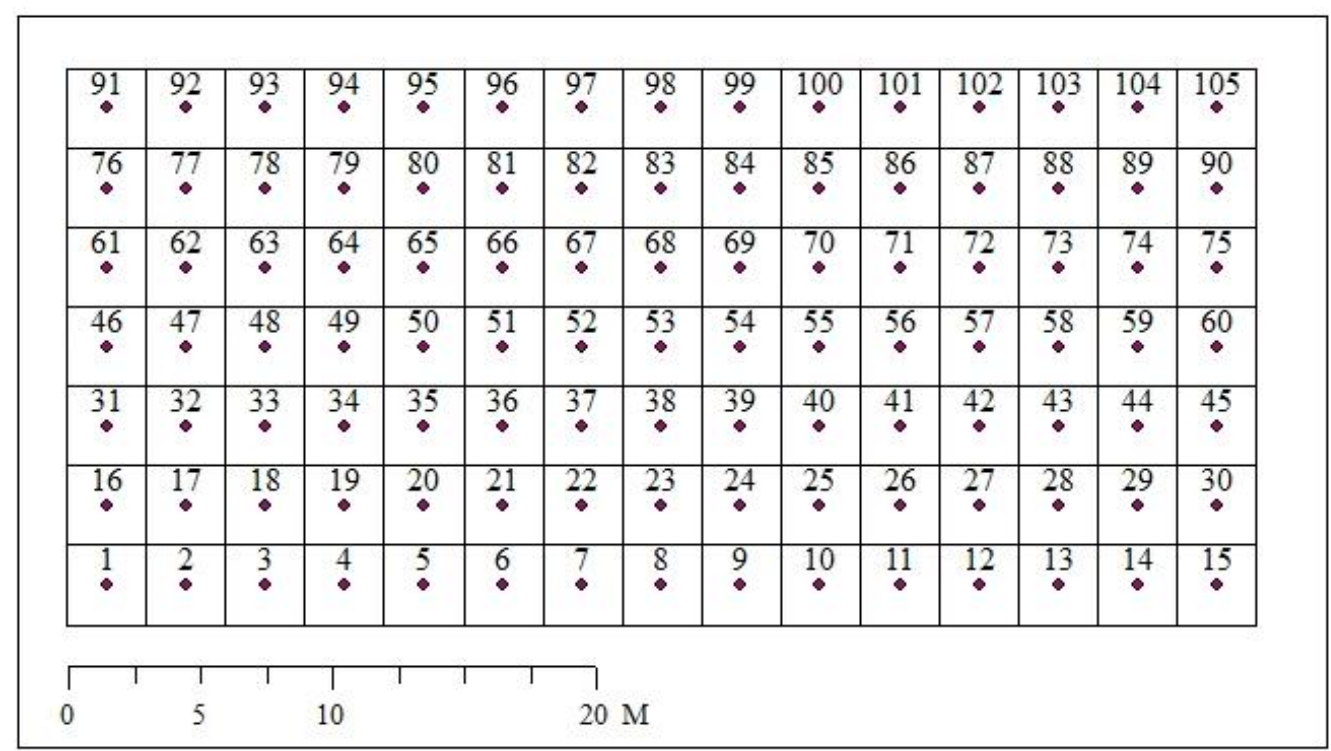

Рис. 1. Схема размещения точек отбора проб в пределах полигона

Расстояние между рядами в полигоне составляет 3 м. В каждой точке были сделаны почвенно-зоологические пробы размером 0,25×0,25 м для количественного учета почвенной макрофауны.

Тип почвы - дерново-лесная черноземовидная глубокая глубокарбонатая глееватая почва. Уровень грунтовых вод с глубины 155 см. Поверхность почвы интенсивно перерыта кабаном.

В пределах каждого квадрата размером $3 \times 3$ м было проведено геоботаническое описание растительности. На исследуемом полигоне растительность представлена 36 видами. Данный фитоценоз по А. Л. Бельгарду (1950, 1971) относится к группе аренных лесов и является дубняком со свежим разнотравьем С2 с полуосветленной световой структурой (Жуков, 2016).

На основании геоботанических описаний выполнено фитоиндикационное оценивание экологических факторов по А. Л. Бельгарду (1950, 1971), Я. П. Дидуху (Diduh, 2011, 2012) и Г. Элленбергу (Ellenberg, 1974). Экоморфы растений приведены по А. Л. Бельгарду $(1950,1971)$ и В. В. Тарасову $(2012)$. Гигроморфы представлены ксерофитами (уровень влажности 1), мезоксерофитами (уровень влажности 2), ксеромезофитами (уровень влажности 3), мезофитами (уровень влажности 4), гигромезофитами (уровень влажности 5). Уровень влажности по гигроморфической структуре (Hygr) оценен как:

$$
\text { Hygr }=\frac{\sum_{i=1}^{\mathrm{i} i \mathrm{~N}}\left(\mathrm{i} \times \mathrm{P}_{\mathrm{i}}\right)}{100},
$$

где і - уровень влажности; Рі - проективное покрытие растений соответствующей гигроморфы.

Трофоморфы представлены олиготрофами (уровень трофности 1), мезотрофами (уровень трофности 2) и мегатрофами (уровень трофности 3). Уровень трофности по трофоморфической структуре (Troph_B) оценен как:

$$
\text { Troph_B }=\frac{\sum_{\mathrm{j}=1}^{\mathrm{j}=\mathrm{N}}\left(\mathrm{j} \times \mathrm{P}_{\mathrm{j}}\right)}{100},
$$

где ј - уровень трофности; Рj - проективное покрытие растений соответствующей трофоморфы.

Гелиоморфы представлены гелиосциофитами (уровень освещения 2), сциогелиофитами (уровень освещения 3), гелиофитами (уровень освещения 4). Уровень освещения по геолиоморфической структуре (Неl) оценен как:

$$
\mathrm{Hel}=\frac{\sum_{z=1}^{\mathrm{z}=\mathrm{N}}\left(\mathrm{z} \times \mathrm{P}_{\mathrm{z}}\right)}{100}
$$

где z - уровень освещения; Pz - проективное покрытие растений соответствующей гелиоморфы.

Фитоиндикационные шкалы по Я. П. Дидуху (Diduh, 2011, 2012) включают эдафические и климатические шкалы. К эдафическим фитоиндикационным шкалам относятся показатели гидроморф (Hd), переменности увлажнения (fH), аэрации (Ae), режима кислотности (Rc), солевого режима (Sl), содержания карбонатных солей (Ca), содержания усвояемых форм азота (Nt). K климатическим шкалам относят показатели терморежима (Tm), омброрежима $(\mathrm{Om})$, криорежима $(\mathrm{Cr})$ и континентальности климата $(\mathrm{Kn})$. Помимо указанных, выделяется ещё шкала освещения (LC), которую характеризуют как микроклиматическую шкалу. Тепловые свойства почв индицируются шкалой терморежима, а гидротермические - шкалой омброрежима. Фитоиндикационное оценивание экологических факторов выполнено по методу идеального индикатора Г. Н. Бузука и О. В. Созинова (Buzuk, Sozinov, 2009).

Фитоиндикационные шкалы Г. Элленберга (Ellenberg, 1974) включают: шкалу освещенности/затенения (9 классов, Light Regime), шкалу термоклимата (9 классов, Temperatures), шкалу континентальности климата (9 классов, Continentality of Climate), шкала увлажнения почв (12 классов, Humidity), шкала кислотности почв (9 классов, Acidity) и шкалу богатства почв азотом (9 классов, Nutrients Availability). Оценка значений экологических 
факторов производилась с помощью метода средних взвешенных значений индикаторных шкал с учетом проективного покрытия растений.

Измерение твердости почв производились в полевых условиях с помощью ручного пенетрометра Eijkelkamp на глубину до 100 см с интервалом 5 см. Средняя погрешность результатов измерений прибора составляет $\pm 8 \%$. Измерения производились конусом с размером поперечного сечения 2 см2. В пределах каждой точки измерения твердости почвы производились в однократной повторности.

Для проведения измерения электропроводности почвы in situ использовался сенсор HI 76305 (Hanna Instruments, Woodsocket, R. І.). Этот сенсор работает совместно с портативным прибором НІ 993310. Тестер оценивает общую электропроводность почвы, т.е. объединенную проводимость почвенного воздуха, воды и частиц. Результаты измерений прибора представлены в единицах насыщенности почвенного раствора солями г/л. Сравнение результатов измерений прибором HI 76305 с данными лабораторных исследований позволили оценить коэффициент перевода единиц как 1 дС/м = 155 мг/л (Pennisi, van lersel, 2002).

Почвенную температуру измеряли в период с 13 до 14 часов цифровыми термометрами WT-1 (ПАO «Стеклоприбор», http://bit.steklopribor.com, точность - 0,1 ${ }^{\circ} \mathrm{C}$ ) на глубине 5-7 см. Измерения температуры сделаны в трехкратной повторности в каждой пробной точке.

Агрегатную структуру оценили методом сухого просеивания по Савинову. Установлено процентное содержание таких фракций: <0,25, 0,25-0,5, 0,5-1, 1-2, 2-3, 3-5, 5-7, 7-10, >10 мм и корни растений. Плотность почвы оценили по Качинскому, влажность почвы - весовым методом (Vadunina, Korchagina, 1986).

Для снижения размерности признакового пространства и предотвращения мультиколлинеарности предикторов результаты измерения свойств среды подвергли анализу главных компонент. Анализ главных компонент выполнен отдельно для эдафических свойств и для фитоиндикационных показателей. Таким образом сформировано две совокупности предикторов свойств среды: эдафические и растительные. Число статистически достоверных главных компонент оценено по процедуре Горна (Horn, 1965). Соответствующие расчеты выполнены с использованием пакета paran (Dinno, 2012).

Матрицу численностей видов почвенных животных стандартизировали с использованием дистанции Хеллинджера перед анализом. Далее был удален линейный тренд сообщества мезопедобионтов. Пространственная структура может быть моделирована с помощью множества независимых пространственных паттернов - главных координат матрицы близости (PCNM - Principal Coordinates of Neighbor Matrices, или болеe позднее название MEMs - Moran's eigenvector maps). Пространственные переменные были вычислены после спектральной декомпозиции усеченной матрицы расстояний между точками отбора проб. Порядок этих переменных соответствует последовательности вариации от крупномасштабной к средне- и детальномасштабной. РCNM-подход позволяет получить n-1 пространственную переменную с позитивными и негативными собственными числами. Для анализа были отобраны в качестве предикторов переменные только с позитивными собственными числами. Прямой выбор переменных среды или пространственных переменных выполнен с помощью функции forward.sel в пакете Packfor (доступный по адресу http://www.bio.umontreal.ca/legendre/). Процедура прямого выбора позволяет отобрать переменные со значимым ( $p$ < 0,05 после 999 пермутаций) вкладом в объясненную вариацию сообщества почвенных животных (Blanchet et al., 2008). Только отобранные переменные использовались для дальнейшего анализа.

Фракционирование вариации (Borcard et al., 1992) выполнено для количественной оценки пропорций вариации композиции сообщества, которые объясняются совокупностью переменных среды или пространственных переменных. Откорректированные значения $R^{2}$ позволили вычислить чистую компоненту окружающей среды, чистую пространственную компоненту и смешанную пространственную и средовую компоненты варьирования сообщества.

Далее анализ избыточности (redundancy analysis - RDA) и линейный регрессионный анализ использовали для того, чтобы выяснить характер зависимости пространственно структурированного варьирования сообщества мезопедобионтов от эдафических и растительных факторов среды на крупномасштабном, среднемасштабном и детальномасштабном пространственных уровнях.

Статистические расчеты проведены с помощью программы Statistica 7.0 и программной оболочки Project R "R: A Language and Environment for Statistical Computing" (http://www.R-project.org/). Оценивание доверительных интервалов и стандартного отклонения численности почвенных животных было произведено с помощью бутстреп-подхода и выполнено средствами пакета bootES (Kirby, Gerlanc, 2013).

\section{Результаты и обсуждение}

В почве исследуемого полигона было при ручной разборке проб обнаружено 44 вида почвенных животных.

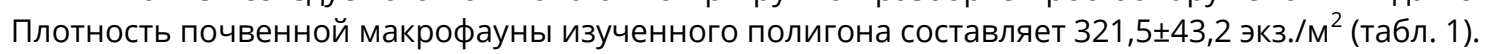

Доминирующей группой по численности являются дождевые черви (Lumbricidae), которые в среднем составили 32,8\% от суммарной численности сообщества. Дождевые черви представлены шестью видами подстилочными Dendrobaena octaedra и Dendrodrilus r. tenuis, двумя собственно почвенными видами Ароrrectodea 
trapezoides и Aporrectodea rosea, норным видом Octodrilus transpadanus и амфибиотическим видом Eiseniella tetraedra.

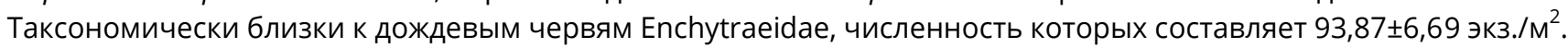

Таблица 1. Видовой состав и обилие почвенной макрофауны

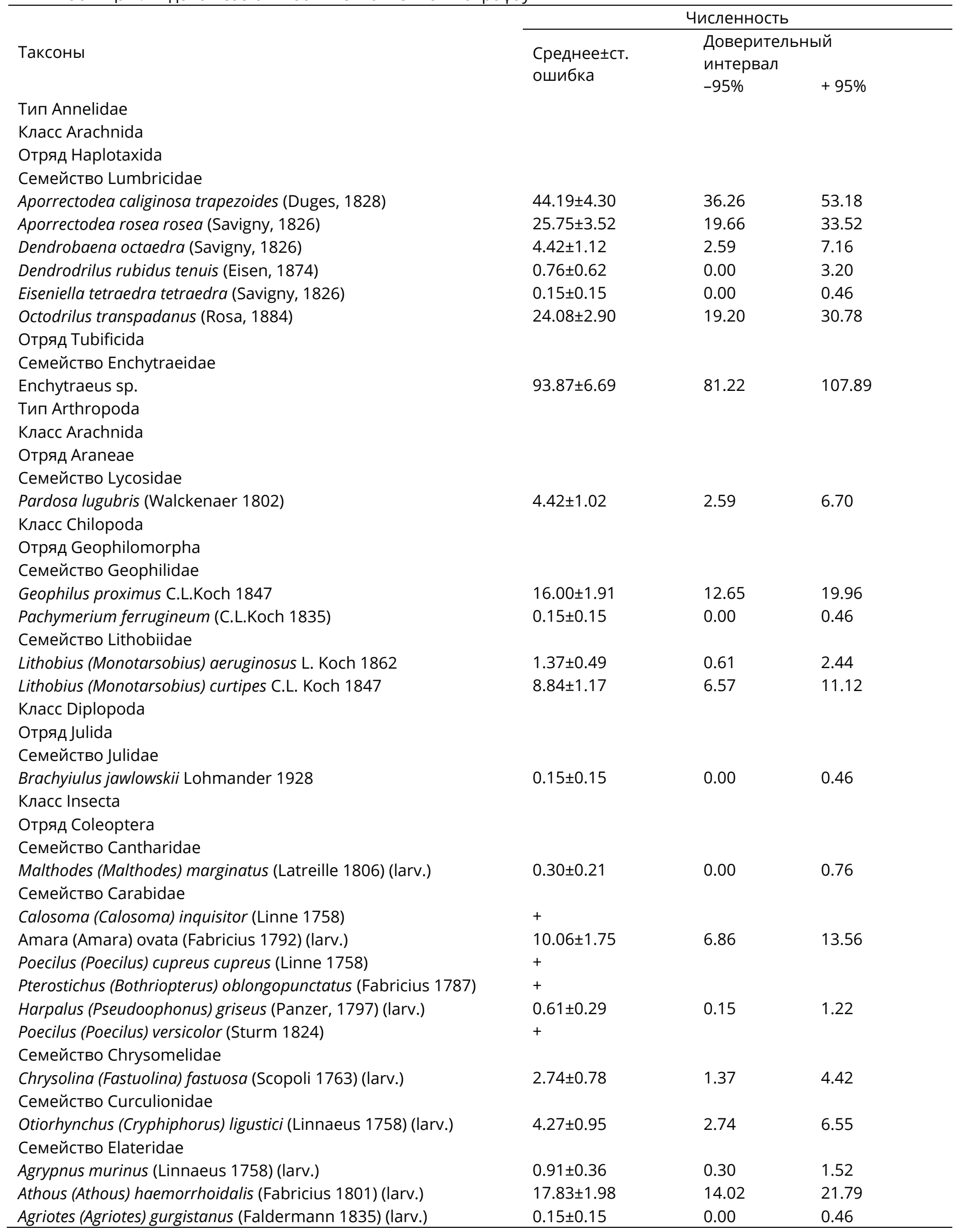




\begin{tabular}{|c|c|c|c|}
\hline \multicolumn{4}{|l|}{ Семейство Silphidae } \\
\hline Dendroxena quadrimaculata (Scopoli 1772) & $0.15 \pm 0.15$ & 0.00 & 0.46 \\
\hline \multicolumn{4}{|l|}{ Семейство Staphylinidae } \\
\hline Platydracus (Platydracus) fulvipes (Scopoli 1763) (larv.) & $2.29 \pm 0.55$ & 1.22 & 3.35 \\
\hline \multicolumn{4}{|l|}{ Семейство Tenebrionidae } \\
\hline Isomira murina (Linnaeus 1758) (larv.) & $0.30 \pm 0.21$ & 0.00 & 0.76 \\
\hline Helops coeruleus (Linnaeus 1758) (larv.) & $1.83 \pm 0.50$ & 0.91 & 2.74 \\
\hline \multicolumn{4}{|l|}{ Семейство Melolonthidae } \\
\hline Amphimallon solstitiale (Linnaeus 1758) (larv.) & $0.15 \pm 0.16$ & 0.00 & 0.46 \\
\hline Melolontha melolontha (Linnaeus 1758) (larv.) & $2.29 \pm 0.54$ & 1.33 & 3.35 \\
\hline Amphimallon assimile (Herbst 1790) (larv.) & $0.15 \pm 0.15$ & 0.00 & 0.46 \\
\hline \multicolumn{4}{|l|}{ Отряд Dermaptera } \\
\hline \multicolumn{4}{|l|}{ Семейство Forficulidae } \\
\hline Forficula auricularia Linnaeus 1758 & $1.83 \pm 0.71$ & 0.76 & 3.66 \\
\hline \multicolumn{4}{|l|}{ Отряд Diptera } \\
\hline \multicolumn{4}{|l|}{ Семейство Therevidae } \\
\hline Thereva nobilitata (Fabricius 1775) (larv.) & $22.25 \pm 2.09$ & 18.29 & 26.41 \\
\hline \multicolumn{4}{|l|}{ Семейство Asilidae } \\
\hline Cyrtopogon lateralis (Fallen 1814) (larv.) & $0.30 \pm 0.22$ & 0.00 & 0.76 \\
\hline \multicolumn{4}{|l|}{ Семейство Dolichopodidae } \\
\hline Dolichopus sp. (larv.) & $0.30 \pm 0.22$ & 0.00 & 0.76 \\
\hline \multicolumn{4}{|l|}{ Семейство Rhagionidae } \\
\hline Rhagio scolopaceus (Linnaeus 1758) (larv.) & $2.74 \pm 0.67$ & 1.52 & 4.11 \\
\hline \multicolumn{4}{|l|}{ Семейство Tabanidae } \\
\hline Tabanus bromius Linnaeus 1758 (larv.) & $4.88 \pm 1.49$ & 2.44 & 8.53 \\
\hline \multicolumn{4}{|l|}{ Семейство Stratiomyidae } \\
\hline Stratiomys longicornis (Scopoli 1763) (larv.) & $1.22 \pm 0.46$ & 0.46 & 2.29 \\
\hline \multicolumn{4}{|l|}{ Семейство Tipulidae } \\
\hline Tipula (Lunatipula) lunata Linnaeus 1758 (larv.) & $0.30 \pm 0.22$ & 0.00 & 0.76 \\
\hline \multicolumn{4}{|l|}{ Отряд Lepidoptera } \\
\hline \multicolumn{4}{|l|}{ Семейство Noctuidae } \\
\hline Agrotis clavis (Hufnagel 1766) (larv.) & $2.74 \pm 0.58$ & 1.52 & 3.81 \\
\hline \multicolumn{4}{|l|}{ Класс Malacostraca } \\
\hline \multicolumn{4}{|l|}{ Отряд Isopoda } \\
\hline \multicolumn{4}{|l|}{ Семейство Trachelipodidae } \\
\hline Trachelipus rathkii (Brandt 1833) & $5.18 \pm 0.72$ & 3.81 & 6.55 \\
\hline \multicolumn{4}{|l|}{ Тип Mollusca } \\
\hline \multicolumn{4}{|l|}{ Класс Gastropoda } \\
\hline \multicolumn{4}{|l|}{ Отряд Pulmonata } \\
\hline Семейство Cochlicopidae & & & \\
\hline Cochlicopa lubrica (O.F. Muller 1774) & $1.98 \pm 0.51$ & 1.07 & 3.05 \\
\hline Семейство Succineidae & & & \\
\hline Succinella oblonga (Draparnaud 1801) & $1.98 \pm 0.52$ & 0.91 & 3.05 \\
\hline Семейство Valloniidae & & & \\
\hline Vallonia pulchella (O.F. Muller 1774) & $2.13 \pm 0.54$ & 1.07 & 3.20 \\
\hline Семейство Vitrinidae & & & \\
\hline Vitrina pellucida (O.F. Muller 1774) & $2.59 \pm 0.58$ & 1.52 & 3.66 \\
\hline Семейство Oxychilidae & & & \\
\hline Aegopinella pura (Alder 1830) & $2.74 \pm 0.59$ & 1.52 & 3.81 \\
\hline Семейство Patulidae & & & \\
\hline Discus (Discus) ruderatus (W. Hartmann 1821) & $0.15 \pm 0.15$ & 0.00 & 0.46 \\
\hline
\end{tabular}

Численность пауков составляет 1,72 \% от суммарного обилия комплекса мезопедобионтов. Более разнообразна и обильна другая группа хищных беспозвоночных - Chilopoda. Они составляют 8,0% от суммарной численности сообщества. Эта группа представлена четырьмя видами, из которых два вида являются подстилочными (Lithobius curtipes, Lithobius aeruginosus), один вид является собственно почвенными (Geophilus 
proximus) и один вид - норником (Pachymerium ferrugineum). Сапротрофные многоножки Diplopoda составляют 1,0\% от суммарной численности сообщества и представлены одним видом Brachyiulus jawlowskii.

Разнообразен комплекс насекомых, который представлен 28 видами. Численность насекомых составляет $24,4 \%$ от суммарного обилия сообщества мезопедобионтов. Представители отрядов Coleoptera, Diptera $и$ Lepidoptera в почве изучаемого полигона находятся на личиночной стадии. Также разнообразна группа наземных моллюсков, которая представлена 6 видами, однако они составляют всего 1,6 \% от суммарной численности сообщества.

Параметры среды обитания почвенных животных представлены 64 переменными: 35 эдафических показателей и 29 показателей растительного покрова. Большое число переменных и их взаимная корреляция делает обоснованным проведение анализа главных компонент как процедуры снижения размерности признакового пространства. Следует отметить, что полученные новые переменные являются ортогональными, т.е. статистически независимыми (табл. 2).

Таблица 2. Описательные статистики и анализ главных компонент эдафических показателей среды (представлены достоверные коэффициенты корреляции $\mathrm{p}<0,05$ )

\begin{tabular}{|c|c|c|c|c|c|c|c|}
\hline \multirow{2}{*}{ Показатель } & & \multicolumn{6}{|c|}{ Главные компоненты } \\
\hline & & 1 & 2 & 3 & 4 & 5 & 6 \\
\hline \multicolumn{8}{|c|}{ Подстилка и температура почвы } \\
\hline Litter, cM & $4.00 \pm 0.091$ & - & 0.61 & - & - & - & -0.31 \\
\hline Temp, ${ }^{\circ} \mathrm{C}$ & $7.35 \pm 0.048$ & - & - & - & - & - & -0.26 \\
\hline \multicolumn{8}{|c|}{ Твердость почвы на глубине, МПа } \\
\hline $0-5 \mathrm{~cm}$ & $1.03 \pm 0.019$ & - & - & - & - & -0.58 & - \\
\hline $5-10 \mathrm{~cm}$ & $1.24 \pm 0.021$ & - & 0.27 & 0.27 & - & -0.76 & - \\
\hline $10-15 \mathrm{~cm}$ & $1.37 \pm 0.030$ & - & 0.17 & 0.50 & - & -0.69 & - \\
\hline $15-20 \mathrm{~cm}$ & $1.40 \pm 0.035$ & - & 0.27 & 0.65 & - & -0.42 & - \\
\hline $20-25 \mathrm{~cm}$ & $1.46 \pm 0.041$ & - & 0.38 & 0.75 & - & - & - \\
\hline $25-30 \mathrm{~cm}$ & $1.49 \pm 0.047$ & -0.21 & 0.53 & 0.63 & 0.24 & - & - \\
\hline $30-35 \mathrm{~cm}$ & $1.56 \pm 0.039$ & -0.32 & 0.51 & 0.49 & 0.20 & 0.29 & - \\
\hline $35-40 \mathrm{~cm}$ & $1.64 \pm 0.043$ & -0.48 & 0.60 & - & 0.16 & 0.27 & - \\
\hline $40-45 \mathrm{~cm}$ & $1.86 \pm 0.051$ & -0.60 & 0.53 & - & 0.19 & 0.26 & - \\
\hline $45-50 \mathrm{~cm}$ & $2.07 \pm 0.056$ & -0.64 & 0.48 & - & 0.19 & 0.23 & - \\
\hline $50-55 \mathrm{~cm}$ & $2.25 \pm 0.052$ & -0.68 & 0.24 & -0.22 & - & - & -0.42 \\
\hline $55-60 \mathrm{~cm}$ & $2.57 \pm 0.065$ & -0.70 & - & -0.35 & - & - & -0.35 \\
\hline $60-65 \mathrm{~cm}$ & $2.84 \pm 0.075$ & -0.74 & - & -0.30 & - & -0.20 & -0.35 \\
\hline $65-70 \mathrm{~cm}$ & $3.20 \pm 0.074$ & -0.81 & - & - & - & -0.21 & -0.26 \\
\hline $70-75 \mathrm{~cm}$ & $3.34 \pm 0.075$ & -0.83 & -0.23 & - & - & -0.21 & - \\
\hline $75-80 \mathrm{~cm}$ & $3.43 \pm 0.077$ & -0.85 & -0.27 & - & - & -0.20 & - \\
\hline $80-85 \mathrm{~cm}$ & $3.60 \pm 0.082$ & -0.84 & -0.31 & - & - & - & - \\
\hline $85-90 \mathrm{~cm}$ & $3.71 \pm 0.083$ & -0.79 & -0.38 & - & - & - & 0.31 \\
\hline $90-95 \mathrm{~cm}$ & $3.83 \pm 0.076$ & -0.74 & -0.42 & - & - & - & 0.38 \\
\hline $95-100 \mathrm{~cm}$ & $3.91 \pm 0.071$ & -0.72 & -0.38 & - & - & - & 0.33 \\
\hline \multicolumn{8}{|c|}{ Другие эдафические показатели } \\
\hline Влажность, \% & $6.08 \pm 0.430$ & - & - & 0.46 & -0.42 & - & -0.33 \\
\hline Плотность, г/см3 & $1.19 \pm 0.015$ & 0.27 & - & -0.38 & 0.57 & - & 0.24 \\
\hline $\mathrm{EC}, \mathrm{ACM} / \mathrm{M}$ & $0.30 \pm 0.007$ & - & -0.20 & -0.24 & - & - & -0.29 \\
\hline \multicolumn{8}{|c|}{ Агрегатные фракции и корни растений, мм, в \% } \\
\hline$>10$ & $11.06 \pm 0.521$ & - & -0.24 & - & 0.70 & -0.22 & - \\
\hline $7-10$ & $9.46 \pm 0.231$ & 0.21 & -0.28 & - & 0.62 & - & -0.21 \\
\hline $5-7$ & $9.14 \pm 0.196$ & - & -0.49 & 0.32 & 0.23 & - & -0.47 \\
\hline $3-5$ & $12.47 \pm 0.234$ & - & -0.39 & 0.50 & - & 0.22 & -0.43 \\
\hline $2-3$ & $19.92 \pm 0.648$ & - & -0.57 & 0.50 & - & 0.24 & - \\
\hline
\end{tabular}




\begin{tabular}{|c|c|c|c|c|c|c|c|}
\hline $1-2$ & $28.61 \pm 0.784$ & - & 0.43 & -0.36 & -0.55 & - & 0.29 \\
\hline $0,5-1$ & $1.17 \pm 0.049$ & -0.22 & 0.43 & - & - & - & - \\
\hline $0,25-0,5$ & $4.90 \pm 0.326$ & - & 0.70 & -0.31 & - & - & - \\
\hline$<0,25$ & $3.39 \pm 0.247$ & - & 0.66 & -0.24 & - & - & - \\
\hline Корни, \% & $0.97 \pm 0.090$ & -0.28 & - & 0.29 & -0.49 & - & - \\
\hline \% дисперсии & & 21.38 & 14.74 & 10.73 & 6.76 & 6.59 & 5.81 \\
\hline $\begin{array}{l}\text { \% объясненной } \\
\text { дисперсии сообщества }\end{array}$ & & 19.14 & 26.98 & 16.92 & 18.48 & 9.89 & 8.59 \\
\hline $\begin{array}{l}\text { Чувствительность } \\
\text { сообщества }\end{array}$ & & 0.90 & 1.83 & 1.58 & 2.73 & 1.50 & 1.48 \\
\hline $\begin{array}{l}\text { Достоверный предиктор } \\
\text { структуры сообщества }\end{array}$ & & + & + & + & + & + & - \\
\hline
\end{tabular}

В результате анализа эдафических характеристик выделено 9 главных компонент, собственные числа которых превышают 1. Процедура Горна (Horn, 1965) позволила установить, что статистически достоверными являются 6 первых главных компонент, которые вместе описывают 66.0 \% общей дисперсии признакового пространства. Главную компоненту 1 можно содержательно интерпретировать как варьирование твердости почвы на глубине 25-100 см. Главная компонента 2 представляет тенденцию противоположного варьирования твердости на глубине 5-55 см с одной стороны и на глубине 70-100 см - с другой. Также эта компонента чувствительна к варьированию агрегатной структуры почвы. Главная компонента 3 отражает тенденцию противоположного варьирования твердости на глубине 5-35 см с одной стороны и на глубине 50-65 см - с другой. Также эта компонента чувствительна к влажности, плотности и электропроводности верхнего почвенного слоя. Главная компонента 4 отражает совместное варьирование плотности и влажности почвы на фоне изменения содержания фракций > 10 мм и 5-7 мм, а также корней растений. Главная компонента 5 отражает взаимно противоположную динамику изменения содержания агрегатных фракций размером > 10 мм с одной стороны и 25 мм - с другой. Главная компонента 6 чувствительна к варьированию твердости почвы преимущественно в средней части измеренного диапазона (50-70 см).

Анализ характеристик растительности позволил установить 10 главных компонент, собственные числа которых превышают 1. Процедура Горна (Horn, 1965) позволила установить, что статистически достоверными являются 7 первых главных компонент, которые вместе описывают 64.2 \% общей дисперсии признакового пространства (табл. 3). Главные компоненты отражают сложный характер взаимосвязи между индикаторными показателями таким образом, что представляет некоторую сложность интерпретировать главные компоненты в терминах первичных экологических факторов. Главная компонента 1 указывает на обратное соотношение в растительном сообществе сильвантов и представителей прочих ценоморф, что объясняет её корреляцию с влажностью и индикатором режима увлажнения. Главная компонента 2 в наибольшей степени связана с рудерантами, что позволяет её интерпретировать как маркер нарушенности растительного покрова. Главная компонента 3 связана с пратантами и характеризуется высокой корреляцией с климатическими экологическими шкалами. Главная компонента 4 отражает соотношение пратантов в сравнении с представителями других ценоморф в сообществе. Главная компонента 5 наиболее чувствительна к режиму влажности, переменности увлажнения и режиму азотного питания. Содержательная интерпретация минорных главных компонент вызывает сложности.

Анализ избыточности свидетельствует о том, что эдафические факторы среды, представленные с помощью главных компонент, описывают 7,0 \% вариабельности сообщества мезопедобионтов (F = 1,73, $p<0,001)$. Процедура прямого выбора позволила установить, что статистически достоверное влияние на структуру сообщества оказывают главные компоненты 1, 2, 3, 4 и 5. С помощью анализа избыточности показано, что показатели свойств растительного покрова, представленные в виде главных компонент, описывают 7,1 \% вариабельности сообщества мезопедобионтов. Процедура прямого выбора позволила установить, что статистически достоверное влияние на структуру сообщества оказывают главные компоненты 2, 3, 4, 6. Эти главные компоненты описывают 3,2 \% вариабельности сообщества $(F=1,84, p<0,001)$.

Таблица 3. Описательные статистики и анализ главных компонент показателей растительности (представлены достоверные коэффициенты корреляции $\mathrm{p}<0,05$ ) 


\begin{tabular}{|c|c|c|c|c|c|c|c|c|}
\hline \multicolumn{9}{|c|}{ Фитоиндикационные шкалы Дидуха } \\
\hline $\mathrm{Hd}$ & $9.41 \pm 0.106$ & 0.47 & 0.24 & - & 0.24 & -0.34 & 0.23 & - \\
\hline $\mathrm{ffl}$ & $4.61 \pm 0.048$ & -0.26 & - & -0.32 & - & -0.41 & - & -0.34 \\
\hline $\mathrm{Rc}$ & $7.13 \pm 0.056$ & -0.53 & - & -0.33 & - & - & - & - \\
\hline SI & $5.22 \pm 0.096$ & -0.45 & - & - & 0.47 & 0.19 & - & -0.25 \\
\hline $\mathrm{Ca}$ & $6.78 \pm 0.109$ & -0.26 & - & -0.42 & - & - & -0.30 & - \\
\hline $\mathrm{Nt}$ & $11.14 \pm 0.062$ & - & - & - & - & 0.40 & - & -0.34 \\
\hline $\mathrm{Ae}$ & $5.23 \pm 0.078$ & -0.25 & -0.40 & - & 0.29 & -0.27 & -0.20 & 0.28 \\
\hline $\mathrm{Tm}$ & $9.95 \pm 0.066$ & -0.41 & - & - & 0.37 & 0.44 & - & - \\
\hline Om & $13.62 \pm 0.089$ & - & - & 0.54 & -0.23 & -0.43 & -0.30 & 0.27 \\
\hline $\mathrm{Kn}$ & $7.59 \pm 0.101$ & 0.35 & - & -0.58 & - & -0.35 & - & - \\
\hline $\mathrm{Cr}$ & $9.07 \pm 0.042$ & -0.37 & - & 0.52 & 0.32 & - & - & 0.25 \\
\hline Lc & $4.99 \pm 0.131$ & -0.59 & - & - & - & - & - & - \\
\hline \multicolumn{9}{|c|}{ Индексы, основанные на экоморфах Бельгарда } \\
\hline Troph_B & $2.38 \pm 0.024$ & - & -0.71 & 0.36 & - & - & 0.22 & -0.32 \\
\hline Hygr_B & $3.25 \pm 0.042$ & -0.53 & 0.60 & -0.23 & - & - & - & 0.22 \\
\hline Hel_B & $2.97 \pm 0.009$ & - & -0.55 & -0.33 & - & 0.22 & -0.30 & 0.30 \\
\hline \multicolumn{9}{|c|}{ Фитоиндикационные шкалы Элленберга } \\
\hline Light Regime & -0.54 & -0.32 & - & - & - & -0.26 & - & -0.54 \\
\hline Temperatures & - & -0.54 & -0.40 & -0.45 & - & - & - & - \\
\hline Continentality of Climate & - & -0.66 & -0.50 & - & 0.25 & - & - & - \\
\hline Humidity & 0.72 & - & - & - & - & - & - & 0.72 \\
\hline Acidity & -0.25 & 0.48 & -0.36 & -0.40 & - & - & - & -0.25 \\
\hline Nutrients Availability & 0.47 & - & 0.41 & - & 0.23 & - & - & 0.47 \\
\hline \multicolumn{9}{|c|}{ Ценоморфы Бельгарда } \\
\hline $\operatorname{Pr}$ & $0.10 \pm 0.006$ & -0.44 & - & 0.20 & -0.71 & - & - & - \\
\hline $\mathrm{Ru}$ & $0.02 \pm 0.005$ & -0.39 & -0.26 & - & 0.21 & -0.27 & - & -0.35 \\
\hline Sil & $0.89 \pm 0.008$ & 0.64 & - & - & 0.46 & 0.27 & - & - \\
\hline \multicolumn{9}{|c|}{ Жизненные формы Раункиера } \\
\hline $\mathrm{Ph}$ & $0.53 \pm 0.023$ & 0.84 & -0.29 & - & - & - & -0.28 & - \\
\hline $\mathrm{nPh}$ & $0.16 \pm 0.011$ & - & 0.77 & - & - & - & - & 0.28 \\
\hline $\mathrm{HKr}$ & $0.08 \pm 0.007$ & -0.43 & - & - & 0.45 & - & - & - \\
\hline $\mathrm{T}$ & $0.18 \pm 0.018$ & -0.72 & -0.29 & - & - & - & 0.43 & - \\
\hline G & $0.06 \pm 0.006$ & -0.42 & 0.43 & - & - & - & - & - \\
\hline \% дисперсии & & 19.00 & 12.72 & 8.88 & 7.59 & 5.87 & 5.46 & 4.67 \\
\hline $\begin{array}{l}\text { \% объясненной } \\
\text { дисперсии сообщества }\end{array}$ & & 2.35 & 15.43 & 26.05 & 30.57 & 0.35 & 22.18 & 3.07 \\
\hline $\begin{array}{l}\text { Чувствительность } \\
\text { сообщества }\end{array}$ & & 0.12 & 1.21 & 2.93 & 4.03 & 0.06 & 4.06 & 0.66 \\
\hline $\begin{array}{l}\text { Достоверный предиктор } \\
\text { структуры сообщества }\end{array}$ & & - & + & + & + & - & + & - \\
\hline
\end{tabular}

Порядок главных компонент отражает их относительный вклад в варьирование признакового пространства показателей среды. Полученные результаты свидетельствуют о том, что вклад главных компонент в варьирование сообщества почвенных животных отличен от уровня варьирования той или иной главной компоненты. Эту особенность отражает показатель чувствительности сообщества мезопедобионтов к действию главных компонент. Чувствительность можно оценить как отношение уникального вклада главной компоненты в варьирование сообщества к доле дисперсии признакового пространства, которая объяснена этой главной компонентой (Zhukov et al., 2017). По этому показателю сообщество мезопедобионтов среди эдафических характеристик наиболее чувствительно к главной компоненте 4 (чувствительность 2,73). Среди показателей растительного покрова наиболее существенное влияние на почвенных мезопедобионтов оказывают главные компоненты 4 и 6 (чувствительность 4.03 и 4.06 соответственно). 
Выделено 72 пространственных переменных PCNM, которые вместе описывают 44,5 \% вариабельности сообщества мезопедобионтов. Процедура прямого выбора позволила выделить 35 пространственных переменных, которые описывают 37,2 \% вариабельности сообщества $(F=2,76, p<0,001)$.

Фракционирование вариации сообщества мезопедобионтов с учетом комбинации параметров среды и пространственных переменных представлено на рисунке 2.
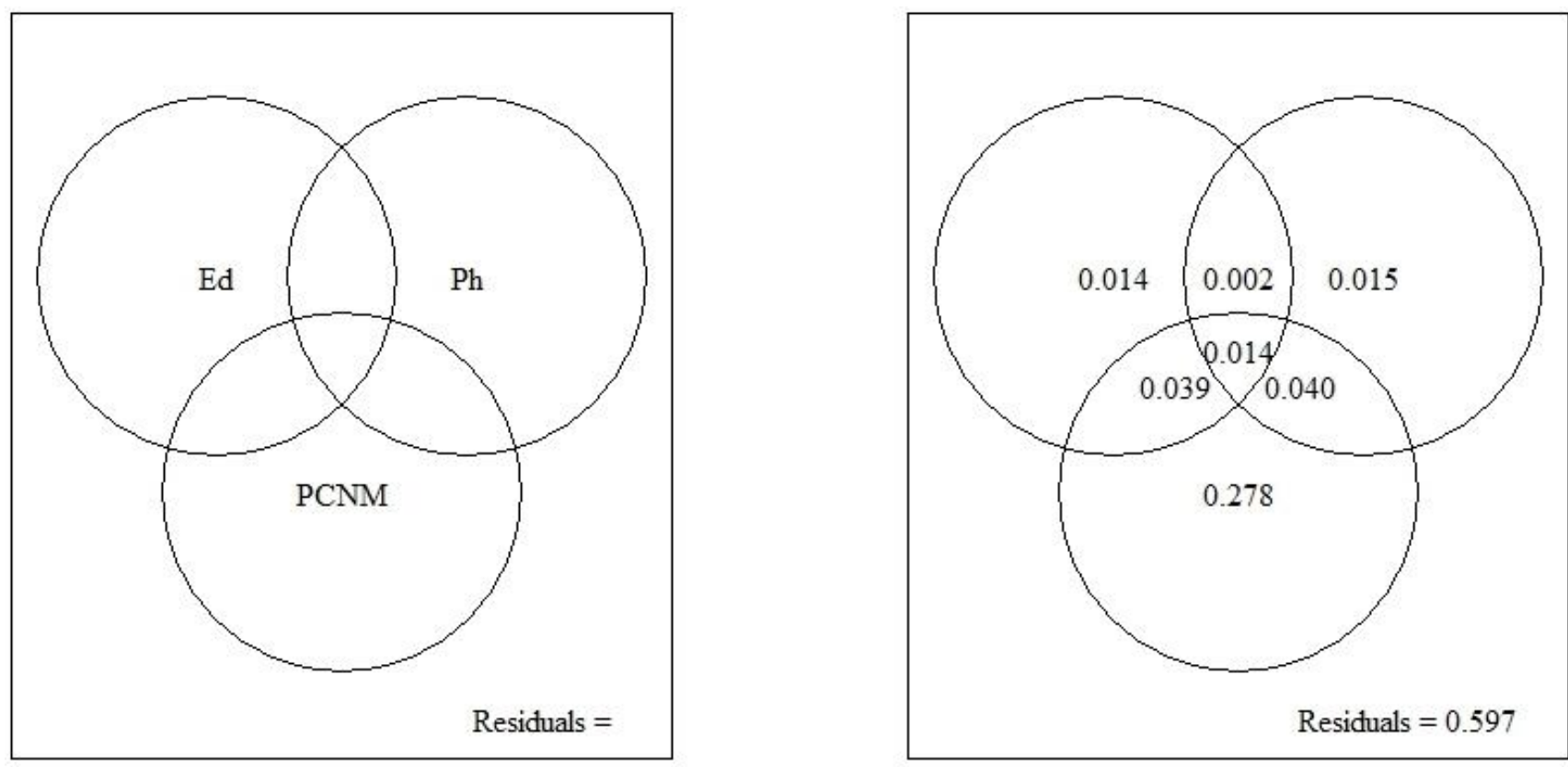

Рис. 2. Фракционирование вариации сообщества мезопедобионтов

Условные обозначения: слева - схема размещения факторов вариации, справа - оценки объясненной вариации; Ed - почвенные факторы среды; Ph - растительные факторы среды; PCNM - пространственные факторы

Почвенные факторы среды после выделения условного эффекта растительных факторов и пространственных переменных описывают 1,4 \% вариабельности сообщества ( $F=1,68, p<0,001)$. Растительные факторы среды после выделения условного эффекта эдафических факторов и пространственных переменных описывают 1,5 \% вариабельности сообщества ( $F=1,61$, p < 0,001). Влияние как эдафических, так и растительных факторов, которое пространственно структурировано, превышает по своей значимости пространственно независимые компоненты соответствующих влияний.

Пространственное и совместное средовое и пространственное влияние было разделено на три компоненты: широкомасштабную (PCNM-переменные 1, 2, 4, 5, 6, 7, 8, 9, 11, 12, 13, 14, 17, 18, 19), среднемасштабную (PCNMпеременные 20, 21, 22, 25, 27, 30, 31, 32, 33, 37, 38, 39) и детальномасштубную (РСNM-переменные 42, 44, 46, 48, 54, $55,57,68)$. Широкомасшабная компонента характеризуется периодичностью пространственного варьирования с длиной волны 24,0-44,5 м, среднемасштабная - 11,1-20,8 м, детальномасштабная - 6,6-11,0 м. Широкомасштабная компонента пространственной изменчивости сообщества описывает 14,6\% вариации ( $F=2,19$, $p<0,001)$, среднемасштабная компонента - 10,3 \% ( $F=1,99, p<0,001)$, детальномасштабная - 3,3\% $(F=1,45, p<0,005)$. Пространственное варьирование канонических осей, которые получены для различных по масштабности пространственных компонент варьирования сообщества почвенных животных, представлено на рисунке 3.

Маркерами осей являются 16 видов почвенных беспозвоночных (табл. 4). Среди них 1 вид маркирует 7 осей (A. trapezoides), 1 вид маркирует 6 осей (A. rosea), 2 вида маркирует 5 осей (A. haemorrhoidalis, Th. nobilitata), 5 видјd маркируют 4 оси (Enchytraeidae sp., G. proximus, L. curtipes, O. transpadanus, T. rathkii), 1 вид маркирует 3 оси (O. ligustici), 2 вида маркируют 2 оси (D. octaedra, P. lugubris) и 4 вида маркируют по одной оси (A. ovata, H. coeruleus, Rh. scolopaceus, V. pellusida).

Пространственные компоненты варьирования сообщества несут информацию как о пространственном аспекте, так и о средовом аспекте реагирования сообщества мезопедобионтов. Регрессионный анализ позволил выявить те главные компоненты, которые характеризуются статистически достоверными регрессионными коэффициентами (табл. 5). 

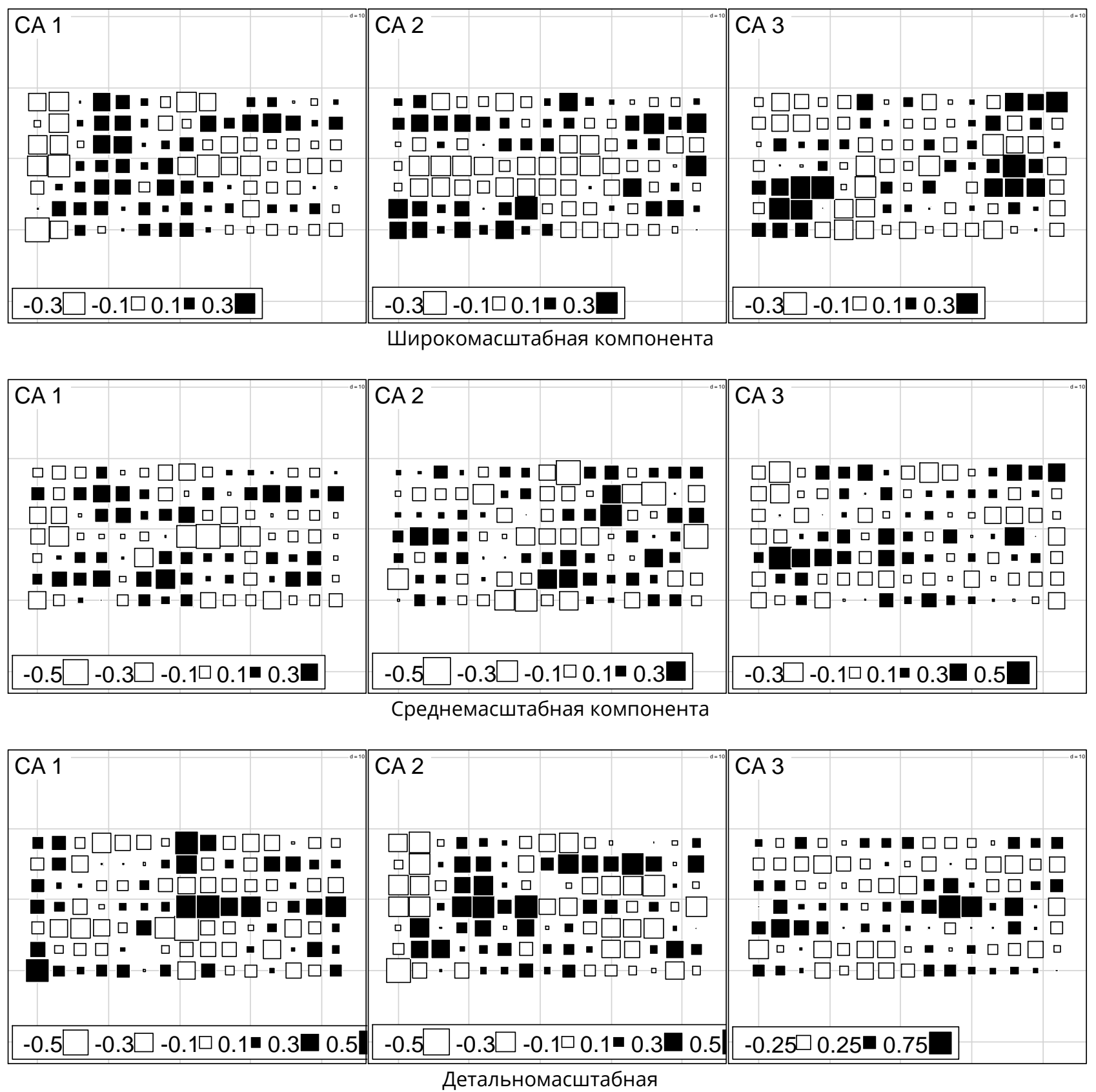

Рис. 3. Пространственное варьирование канонических осей, которые описывают различные масштабные уровни пространственной зависимости почвенной макрофауны

Таблица 4. Виды с наибольшими показателями канонических осей по модулю

\begin{tabular}{|c|c|c|c|c|c|c|c|c|}
\hline \multicolumn{3}{|c|}{ Широкомасштабная компонента } & \multicolumn{3}{|c|}{$\begin{array}{l}\text { Среднемасштабная } \\
\text { компонента }\end{array}$} & \multicolumn{3}{|c|}{$\begin{array}{l}\text { Детальномасштабная } \\
\text { компонента }\end{array}$} \\
\hline RDA1 & RDA2 & RDA3 & RDA1 & RDA2 & RDA3 & RDA1 & RDA2 & RDA3 \\
\hline \multicolumn{9}{|c|}{ Три вида с наибольшим значением канонических осей } \\
\hline $\begin{array}{l}\text { Octodrilus } \\
\text { transpadan } \\
\text { us }\end{array}$ & $\begin{array}{l}\text { Amara } \\
\text { ovata }\end{array}$ & $\begin{array}{l}\text { Pardosa } \\
\text { lugubris }\end{array}$ & $\begin{array}{l}\text { Geophilus } \\
\text { proximus }\end{array}$ & $\begin{array}{l}\text { Aporrectod } \\
\text { ea } \\
\text { trapezoides }\end{array}$ & $\begin{array}{l}\text { Trachelipus } \\
\text { rathkii }\end{array}$ & $\begin{array}{l}\text { Otiorhynch } \\
\text { us ligustici }\end{array}$ & $\begin{array}{l}\text { Octodrilus } \\
\text { transpadan } \\
\text { us }\end{array}$ & $\begin{array}{l}\text { Trachelipus } \\
\text { rathkii }\end{array}$ \\
\hline $\begin{array}{l}\text { Enchytraei } \\
\text { dae sp. }\end{array}$ & $\begin{array}{l}\text { Vitrinia } \\
\text { pellusida }\end{array}$ & $\begin{array}{l}\text { Dendrobae } \\
\text { na } \\
\text { octaedra }\end{array}$ & $\begin{array}{l}\text { Aporrectod } \\
\text { ea rosea }\end{array}$ & $\begin{array}{l}\text { Geophilus } \\
\text { proximus }\end{array}$ & $\begin{array}{l}\text { Dendrobae } \\
\text { na } \\
\text { octaedra }\end{array}$ & $\begin{array}{l}\text { Athous } \\
\text { haemorrho } \\
\text { idalis }\end{array}$ & $\begin{array}{l}\text { Lithobius } \\
\text { curtipes }\end{array}$ & $\begin{array}{l}\text { Aporrectod } \\
\text { ea } \\
\text { trapezoides }\end{array}$ \\
\hline $\begin{array}{l}\text { Athous } \\
\text { haemorrho } \\
\text { idalis }\end{array}$ & $\begin{array}{l}\text { Aporrectod } \\
\text { ea rosea }\end{array}$ & $\begin{array}{l}\text { Octodrilus } \\
\text { transpadan } \\
\text { us }\end{array}$ & $\begin{array}{l}\text { Enchytraei } \\
\text { dae sp. }\end{array}$ & $\begin{array}{l}\text { Enchytraei } \\
\text { dae sp. }\end{array}$ & $\begin{array}{l}\text { Octodrilus } \\
\text { transpadan } \\
\text { us }\end{array}$ & $\begin{array}{l}\text { Aporrectod } \\
\text { ea } \\
\text { trapezoides }\end{array}$ & $\begin{array}{l}\text { Geophilus } \\
\text { proximus }\end{array}$ & $\begin{array}{l}\text { Lithobius } \\
\text { curtipes }\end{array}$ \\
\hline
\end{tabular}




\begin{tabular}{|c|c|c|c|c|c|c|c|c|}
\hline \multicolumn{9}{|c|}{ Три вида с наименьшим значением канонических осей } \\
\hline $\begin{array}{l}\text { Aporrectod } \\
\text { ea } \\
\text { trapezoides }\end{array}$ & $\begin{array}{l}\text { Trachelipus } \\
\text { rathkii }\end{array}$ & $\begin{array}{l}\text { Athous } \\
\text { haemorrho } \\
\text { idalis }\end{array}$ & $\begin{array}{l}\text { Aporrectod } \\
\text { ea } \\
\text { trapezoides }\end{array}$ & $\begin{array}{l}\text { porrectod } \\
\text { a rosea }\end{array}$ & $\begin{array}{l}\text { Aporrectod } \\
\text { ea rosea }\end{array}$ & $\begin{array}{l}\text { Enchytraei } \\
\text { dae sp. }\end{array}$ & $\begin{array}{l}\text { Aporrectod } \\
\text { ea } \\
\text { trapezoides }\end{array}$ & $\begin{array}{l}\text { Aporrectod } \\
\text { ea rosea }\end{array}$ \\
\hline $\begin{array}{l}\text { Trachelipus } \\
\text { rathkii }\end{array}$ & $\begin{array}{l}\text { Lithobius } \\
\text { curtipes }\end{array}$ & $\begin{array}{l}\text { Litho } \\
\text { curti }\end{array}$ & $\begin{array}{l}\text { The } \\
\text { nok }\end{array}$ & $\begin{array}{l}\text { Athous } \\
\text { haemorrho } \\
\text { idalis }\end{array}$ & & & ectod & $\begin{array}{l}\text { Athous } \\
\text { haemorrho } \\
\text { idalis }\end{array}$ \\
\hline $\begin{array}{l}\text { Helops } \\
\text { coeruleus }\end{array}$ & $\begin{array}{l}\text { Thereva } \\
\text { nobilitata }\end{array}$ & $\begin{array}{l}\text { Thereva } \\
\text { nobilitata }\end{array}$ & $\begin{array}{l}\text { Rhagio } \\
\text { scolopaceu } \\
\text { s }\end{array}$ & $\begin{array}{l}\text { Otiorhynch } \\
\text { us ligustici }\end{array}$ & $\begin{array}{l}\text { Aporrectod } \\
\text { ea } \\
\text { trapezoides }\end{array}$ & $\begin{array}{l}\text { Thereva } \\
\text { nobilitata }\end{array}$ & $\begin{array}{l}\text { Thereva } \\
\text { nobilitata }\end{array}$ & $\begin{array}{l}\text { Otiorhynch } \\
\text { us ligustici }\end{array}$ \\
\hline
\end{tabular}

Пространственные компоненты варьирования сообщества несут информацию как о пространственном аспекте, так и о средовом аспекте реагирования сообщества мезопедобионтов. Регрессионный анализ позволил выявить те главные компоненты, которые характеризуются статистически достоверными регрессионными коэффициентами (табл. 5).

Таблица 5. Результаты регрессионного анализа влияния параметров среды на пространственные компоненты варьирования сообщества мезопедобинтов (представлены статистически достоверные предикторы)

\begin{tabular}{|c|c|c|c|c|c|c|c|c|c|}
\hline \multirow{2}{*}{$\begin{array}{l}\text { Параметры } \\
\text { регрессионных } \\
\text { моделей }\end{array}$} & \multicolumn{3}{|c|}{$\begin{array}{l}\text { Широкомасштабная } \\
\text { компонента }\end{array}$} & \multicolumn{3}{|c|}{$\begin{array}{l}\text { Среднемасштабная } \\
\text { компонента }\end{array}$} & \multicolumn{3}{|c|}{$\begin{array}{l}\text { Детальномасштабная } \\
\text { компонента }\end{array}$} \\
\hline & RDA1 & RDA2 & RDA3 & RDA1 & RDA2 & RDA3 & RDA1 & RDA2 & RDA3 \\
\hline $\begin{array}{l}\text { Эдафические } \\
\text { главные компоненты }\end{array}$ & $1,3,6$ & 2,4 & 2 & 1,4 & - & 2,6 & - & - & $1,4,5$ \\
\hline $\begin{array}{l}\text { Растительные } \\
\text { главные компоненты }\end{array}$ & 3 & 2 & 1,4 & 2 & 4 & 3 & - & 3,4 & - \\
\hline$R_{\mathrm{a}}^{2}$ & 0,37 & 0,30 & 0,48 & 0,19 & 0,29 & 0,36 & 0,03 & 0,34 & 0,34 \\
\hline p-уровень & 0,0001 & 0,001 & 0,0001 & 0,07 & 0,002 & 0,0001 & 0,25 & 0,0001 & 0,0001 \\
\hline
\end{tabular}

Установлено, что регрессионная модель влияния параметров среды на пространственные компоненты варьирования сообщества мезопедобионтов может объяснить 3-48 \% их изменчивости. При этом наибольшая роль средовых факторов характерна для широкомасштабной компоненты (30-48 \%), несколько ниже эта роль для среднемасштабной компоненты (19-36 \%) и наименьшая объяснительная способность регрессионной модели характерна для детальномасштабной компоненты (3-34\%). Статистическая значимость одной регрессионной модели для среднемасштабной компоненты и одной для детальномасштабной - выше критического уровня $\mathrm{p}=$ 0,05. Таким образом, можно признать, что среднемасштабная ось RDA1 и детальномасштабная ось RDA1 в основном несут информацию о пространственном варьировании сообщества.

\section{Обсуждение}

Почвенные экосистемы являются насыщенными видами, однако до сих пор остается неизвестной причина такого видового разнообразия (Wardle, 2006). Предполагается, что почвенные животные характеризуются низкой специализацией, что в большей степени характерно для прочих менее разнообразных экосистем (Anderson, 1975; Maraun et al., 2003; Digel et al., 2014). Высокое разнообразие почвенных экосистем объясняется трехмерной природой почвенного тела и короткомасштабными градиентами ресурсов и условий, что позволяет обеспечить высокий уровень расхождения экологических ниш (Takeda, 1987; Berg, Bengtsson, 2007). Возможно также то, что в действительности животные имеют гораздо более различные трофические предпочтения, чем предполагалось paнeе (Jorgensen et al., 2003; Schneider et al., 2004).

В результате проведенного исследования установлено, что плотность населения мезопедобионтов в

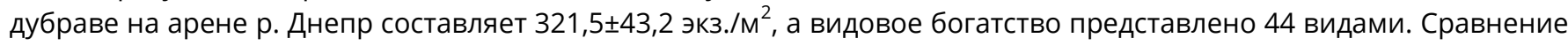
с биотопами в пределах арены р. Днепр свидетельствует о достаточно экстремальных условиях для почвенных животных в почве поймы, так как видовое богатство и численность в данном биотопе находится на низком уровне. Так, сбор данных по однотипной методике показал, что мезопедобионты широколиственного леса на арене р. Днепр представлены 45 видами с численностью 305,37 экз./м² (Zhukov et al., 2015), луга - 47 видов с численностью 254,63 экз./м², болота - 59 видов с численностью 197,49 экз./м² (неопубликованные данные), в

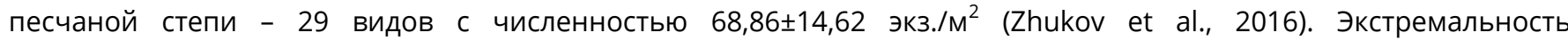
местообитания проявляет себя в низком уровне численности и видового богатства сообщества, что является результатом действия лимитирующего (или лимитирующих) фактора. Для выявления природы лимитирующих факторов нами изучены эдафические свойства и проведена синфитоиндикация экологических факторов в тех же точках, где изучены почвенные животные. 
Общий список обнаруженных сосудистых растений в пределах изученного полигона составляет 60 видов (8,7 видов в одном сайте) (Zhukov et al., 2017). И. А. Цаценкин (Tsatsenkin, 1970) считает, что для надежной синфитоиндикации достаточно 5 видов растений в описании. Таким образом, видовое богатство растительного покрова характеризуется достаточным уровнем для того, чтобы использовать фитоиндикационное оценивание для описания пространственного варьирования эдафических и климатических свойств местообитания. Фитоиндикационные оценки интегрируют вариабельность режимов в профиле почве на значительную глубину, которая определяется глубиной проникновения корневых систем растений. Кроме того, интеграция происходит в пределах площадки, в пределах которой сделано каждое геоботаническое описание, так как её размер значительно превосходит размеры почвенно-зоологической пробы. Размеры «точки» для сообщества почвенных животных $(0,25 \times 0,25$ м) и растительного сообщества (3×3 м) различны. Следует также указать интеграцию динамики почвенных свойств во времени в фитоиндикационных оценках.

Трудоемкость проведения почвоведческих измерений вызывает определенные сложности для изучения их пространственного варьирования, так как для решения этой задачи требует их значительной повторности. Нами измерена твердость почвы в каждой точке отбора почвенно-зоологических проб на глубину 1 м. Также в каждой точке в поверхностном слое почвы измерены температура, влажность, плотность и фракционный состав. Проведенный анализ главных компонент свидетельствует о том, что как эдафические свойства, измеренные на глубину почвенного слоя, так и те, которые измерены только в поверхностном слое, характеризуются высокой степенью корреляции с общими главными компонентами. Это позволяет утверждать, что выбранная модель измерения эдафических показателей дает оценку варьирования свойств почвы как целого образования.

В результате анализа почвенных показателей выявлены 6 главных компонент, а анализа растительности - 7 главных компонент, которые являются статистически достоверными по процедуре Горна (Horn, 1965). Процедура анализа главных компонент позволяет решить несколько задач. Это снижение размерности признакового пространства, с помощью которого характеризуются экологические свойства среды. А также решение проблемы мультиколинеарности - взаимной корреляции большинства эдафический свойств. Полученные главные компоненты являются ортогональными и в этом смысле полностью соответствуют требованиям для дальнейшего статистического анализа.

В отношении влияния на структуру сообщества роль факторов среды различна и не соотносится с их относительной вариабельностью. Процедура прямого выбора позволила установить, что из 6 эдафических главных компонент достоверными предикторами структуры сообщества почвенных животных являются 5, а из 7 растительных - 4. Сообщество мезопедобионтов наиболее чувствительно к минорным главным компонентам, т.е. таким, которые характеризуются относительно малым собственным числом. Этот результат справедлив как в отношении эдафических показателей, так и показателей растительности. Минорные факторы отражают сравнительно малые флуктуации свойств среды, но эти изменения выходят существенно за оптимальные рамки для почвенных животных данного сообщества.

Помимо факторов среды для описания организации сообщества почвенных животных использовались пространственные переменные, или РСNM-переменные. Их исходное число и свойства определяются взаимной конфигурацией в пространстве точек отбора проб. Наша модель отбора проб порождает 55 PCNM-переменных. Из них с помощью процедуры прямого выбора производится селекция тех, которые наилучшим образом описывают структуру сообщества мезопедобионтов. Для сообщества дождевых червей наблюдалась несколько иная картина: 33,0 \% вариации сообщества описывалось факторами среды и только 1,8 \% - пространственной компонентой (Jiménez et al., 2014). Авторы считают, что такой результат находится в соответствии с моделью Хатчинсона контроля сообщества факторами среды. Можно предположить, что изученное нами сообщество организовано в большей степени под воздействием факторов нейтральной природы. Однако, пространственную компоненту варьирования в полной мере нельзя отождествлять с нейтральной компонентой структурирования сообщества. Так, включение в рассмотрение почвенных данных существенно снижало количество вариации структуры сообщества, объясненное пространством, таким образом, снижая важность «нейтральной» компоненты (Baldeck et al., 2013, Chang et al., 2013).

Структура сообществ почвенных животных демонстрирует значительную вариабельность на микроуровне (< 1 м). В формировании такой мозаичности принимают активное участие такие свойства почвы, как структура порового пространства, почвенный микроклимат, структура корневых систем растений, структура наземного растительного покрова (Berg, Bengtsson, 2007; Berg, 2012; Viketoft, 2013). Почвенные организмы также характеризуются пространственными паттернами на мезоуровне (1-100 м) (Saetre, 1999; Ettema et al., 2000; Jimenez et al., 2006; Widenfalk et al., 2015). На этом уровне имеют важность такие свойства среды, как градиенты почвенного рН, влажности и состава растительного покрова (Ettema, Wardle, 2002; Berg, 2012).

В свою очередь, пространственная компонента варьирования сообщества была фракционирована на три масштабных компоненты: детальномасштабную, среднемасштабную и широкомасштабную. В результате проведенного регрессионного анализа установлено, что объясненная дисперсия снижается от широкомасштабной компоненты к детальномасштабной. Межвидовые взаимодействия - конкуренция и хищничество, различия индивидуального участка и ограничения в расселении могут оказывать влияние на структуру сообщества почвенных животных на малых масштабных уровнях (Gonzalez, 2009; Martins da Silva et al., 
2012). Можно предположить, что широкомасштабная компонента и в меньшей степени - среднемасштабная компонента, отражают варьирование пространственно структурированных факторов среды, тогда как детальномасштабная компонента в наибольшей степени может быть интерпретирована как та, которая отражает нейтральный аспект структурирования сообщества. Такой результат получен при изучении макрофауны песчаной степи (Zhukov et al., 2016). Для изученного сообщества различные масштабные компоненты пространственного варьирования не отличаются существенно по степени их согласованности с факторами среды (табл. 1). Для широкомасштабной компоненты большее значение имеют экологические факторы растительной природы, для среднемасштабной - эдафические факторы, для детальномасштабной - как растительные, так и эдафические. Необходимо отметить, что масштабность компонент имеет условный характер. Вполне возможно ожидать наличие процессов динамики сообщества мезопедобионтов нейтральной природы и на уровне, который в работе обозначен как «широкомасштабный». Это вполне закономерно, так как сообщество почвенных животных представлено различными с точки зрения миграционной способности экологическими группами. Крупные подстилочные членистоногие способны перемещаться на значительные дистанции, тогда как более мелкие или собственно почвенные формы имеют значительно более узкий индивидуальный ареал.

\section{Заключение}

В результате проведенного исследования установлено, что причинами структурирования сообщества почвенной макрофауны являются эдафические, растительные и пространственные факторы. Роль этих факторов различна на детально масштабном, среднемасштабном и широкомасштабном пространственных уровнях. Варьирование структуры сообщества под влиянием эдафических и растительных факторов можно отнести к категории детерминистского воздействия, которое осуществляется в рамках теории экологической ниши. Пространственную компоненту варьирования можно отнести к результатам действия факторов нейтральной природы. Однако следует отметить, что пространственное варьирование растительного сообщества также подчиняется действию детерминистских и нейтральных факторов. Это проявляет себя в их пространственной структурированности. Аналогичную природу имеет и пространственное варьирование почвенных свойств. Почва как среда обитание испытывает структурирующее влияние растительного покрова, откуда возникают пространственные паттерны почвенных свойств. Масштабные эффекты варьирования в пространстве проявляют себя по-разному для представителей различных экологических групп макрофауны. Для подстилочных форм в наибольшей степени характерны пространственные паттерны на крупно- и среднемасштабном уровне, а для собственно почвенных форм и норников - на детальномасштабном уровне.

\section{References}

Adler, P. B., HilleRisLambers, J., Levine, J. M. (2007). A niche for neutrality. Ecology Letters, 10, 95-104.

Amarasekare, P. (2003). Competitive coexistence in spatially structured environments: a synthesis. Ecology Letters, 6 , 1109-1122.

Anderson, J.M. (1975). In: Van ek, J. (Ed.), The Enigma of Soil Animal Species Diversity. Czech Republic, Academia, Prague, 51-57.

Anderson, M. J. (2011). Navigating the multiple meanings of $\beta$-diversity: a roadmap for the practicing ecologist. Ecology Letters, 14, 19-28.

Baldeck, C. A. et al. (2013). Soil resources and topography shape local tree community structure in tropical forests. Proceedings of the Royal Society. B 280, 2012-2032.

Barot, S. \& Gignoux, J. (2004). Mechanisms promoting plant coexistence: can all the proposed processes be reconciled? Oikos, 106, 185-192.

Belgard, A.L. (1971). Steppe Forestry. Moscow: Forest Industry (in Russian).

Belgard, A.L., 1950. Forest vegetation of South-Eeast part of the USSR. Kiev: Kiev State University (in Russian).

Belyea, L.R., Lancaster, (1999). Assembly rules within a contingent ecology. Oikos, 86(3), 402-416.

Berg, M.P., Bengtsson, J., 2007. Temporal and spatial variability in soil food web structure. Oikos 116, 1789-1804.

Blanchet, F.G., Bergeron, J.A.C., Spence, J.R., He, F. (2013). Landscape effects of disturbance, habitat heterogeneity and spatial autocorrelation for a ground beetle (Carabidae) assemblage in mature boreal forest. Ecography. 36, 636-647.

Blanchet, F.G., Legendre, P., Borcard, D. (2008). Forward selection of explanatory variables. Ecology, 89(9), $2623-2632$.

Borcard, D., Legendre, P. (1994). Environmental control and spatial structure in ecological communities: an example using oribatid mites (Acari, Oribatei). Environmental and Ecological Statistics. 1, 37-61.

Borcard, D., Legendre, P., Avois-Jacquet, C., Tuosimoto, H. (2004). Dissecting the spatial structure of ecological data at multiple scales. Ecology. 85, 1826-1832.

Borcard, D., Legendre, P., Drapeau, P. (1992). Partialling out the spatial component of ecological variation. Ecology. 73, 1045-1055.

Buzuk, G. N., Sozinov, O. V. (2009). Regression analysis in the bioindication. Botany. Minsk: Pravo i ekonomika. 37, 356-362. (in Russian). 
Dubinina, Y.Y. The spatial scaling of impact in edaphic and plant factors... Acta Biologica Sibirica, 2018, 4(3), 36-53

Cadotte, M.W., Fukami, T. (2005). Dispersal, spatial scale and species diversity in a hierarchically structured experimental landscape. Ecology Letters, 8, 548-557.

Caruso T., Taormina M., Migliorini M. (2012). Relative role of deterministic and stochastic determinants of soil animal community: a spatially explicit analysis of oribatid mites. J. Anim. Ecol., 81(1), 214-221. doi: 10.1111/j.13652656.2011.01886.x.

Chang, L., Zeleny, D., Li, C., Chiu, S., Hsieh, C. (2013). Better environmental data may reverse conclusions about nicheand dispersal-based processes in community assembly. Ecology, 94, 2145-2151.

Chase, J.M. (2003). Community assembly: when should history matter? Oecologia, 136, 489-498.

Chave, J. (2004). Neutral theory and community ecology. Ecology Letters, 7, 241-253.

Clark, J. S. 2012. The coherence problem with the unified neutral theory of biodiversity. Trends in Ecology and Evolution 27:199-203.

Decaëns, T., Jiménez, J.J., Rossi, J.-P. (2009). A null-model analysis of the spatio-temporal distribution of earthworm species assemblages in Colombian grasslands. Journal of Tropical Ecology. 25(4), 415-427.

Decaëns, T., Rossi, J.-P. (2001). Spatio-temporal structure of earthworm community and soil heterogeneity in a tropical pasture, 24(6), 671-682.

Diduh, Y. P. (2012). The principles of the bioindication. Kyiv: Naukova dumka (in Ukranian).

Didukh, Y. P., Fitsailo, T. V., Korotchenko, I.A., Yakushenko, D. M., Pashkevych, N. A. (2011). Biotopes of Forest and Forest-Steppe zones of Ukraine. Kyiv, LLC MACROS.

Didukh, Ya.P. (2011). The ecological scales for the species of Ukrainian flora and their use in synphytoindication. Kyiv: Phytosociocentre.

Digel, C., Curtsdotter, A., Riede, J., Klarner, B., Brose, U. (2014). Unravelling the complex structure of forest soil food webs: higher omnivory and more trophic levels. Oikos, 123, 1157-1172.

Dornelas, M. (2010). Disturbance and change in biodiversity. Philosophical Transactions of the Royal Society B, 365, 3719-3727.

Drake, J.A. (1990). Communities as assembled structures: do rules govern pattern? TREE, 5, 159-164.

Dray, S., Legendre, P., Peres-Neto, P. (2006). Spatial modelling: a comprehensive framework for principal coordinate analysis of neighbours matrices (PCNM). Ecological Modelling, 196, 483-493.

Ellenberg, H. (1974). Zeigerwerte der Gefässpflanzen Mitteleuropas. Scripta geobotanica. Göttingen, 9, 197.

Ellwood, M.D., Manica, F.A., Foster, W.A. (2009). Stochastic and deterministic processes jointly structure tropical arthropod communities. Ecology Letters, 12, 277-284.

Ettema, C., Wardle, D.A. (2002). Spatial soil ecology. Trends in Ecology, Evolution. 17, 177-183.

Ettema, C.H., Rathbun, S.L., Coleman, D.C. (2000). On spatiotemporal patchiness and the coexistence offive species of Chronogaster (Nematoda : Chronogasteridae) in a riparian wetland. Oecologia, 125, 444-452.

Ettema, C.H., Wardle, D.A. (2002). Spatial soil ecology. Trends in Ecology and Evolution, 17, 177-183.

Fukami, T. (2010). Community assembly dynamics in space. Community Ecology: Processes, Models, and Applications.

Eds. Verhoef, H.A., Morin, P.J. - Oxford University Press. Oxford.

Gazol, A. \& Ibanez, R. (2010). Plant species composition in a temperate forest: Multi-scale patterns and determinants. Oecologia, 36, 634-644.

Gonzalez, A., 2009. Metacommunities: Spatial Community Ecology. Wiley, Hoboken, NJ.

Dinno, A., 2012. paran: Horn's test of principal components/factors. R package version 1.5.1. [cit. 2017-11-03]. https://CRAN.R-project.org/package=paran

Horn, J.L.,1965. A rationale and a test for the number of factors in factor analysis. Psychometrika, 30: $179-185$.

Hu, Y.-H., D.-Y. Sheng, Y.-Z. Xiang, Z.-J. Yang, D.-P. Xu, N.-N. Zhang, and L.-L. Shi. 2013. The environment, not space, dominantly structures the landscape patterns of the richness and composition of the tropical understory vegetation. PLoS ONE 8:e81308.

Hubbell, S. P. (2001). The unified neutral theory of biodiversity and biogeography. Princeton University Press, Princeton, New Jersey, USA.

Hutchinson, G. E. (1957). Concluding remarks. Cold Spring Harbour Symposium on Quantitative Biology. 22, 415-427.

Hutchinson, G. E. (1965). The niche: an abstractly inhabited hypervolume. The ecological theatre and the evolutionary play. New Haven, Yale Univ. Press.

Jiménez, J. J., Decaëns, T., Lavelle, P., Rossi, J.-P. (2014). Dissecting the multi-scale spatial relationship of earthworm assemblages with soil environmental variability, BMC Ecology, 14-26. https://doi.org/10.1186/s12898-014-0026-4

Jiménez, J.J., Decaëns, T., Rossi, J.-P. (2012). Soil environmental heterogeneity allows spatial co-occurrence of competitor earthworm species in a gallery forest of the Colombian “Llanos”. Oikos. 121, 915-926.

Jorgensen, H.B., Elmholt, S., Petersen, H. (2003). Collembolan dietary specialisation on soil grown fungi. Biology and Fertility of Soils, 39, 9-15.

Karpachevsky, L. O., 2005. Ecological soil science. Moscow: Geos (in Russian).

Kirby, K. N., Gerlanc, D. BootES: An R package for bootstrap confidence intervals on effect sizes. Behavior Research Methods, 45, 905-927. 
Dubinina, Y.Y. The spatial scaling of impact in edaphic and plant factors... Acta Biologica Sibirica, 2018, 4(3), 36-53

Laliberte, A.S., Rango, A., Herrick, J.E., Fredrickson, E.L., Burkett, L. (2009). An object-based image analysis approach for determining fractional cover of senescent and green vegetation with digital plot photography. Journal of Arid Environments. $69,1-14$.

Laliberte, E., Paquette, A., Legendre, P. \& Bouchard, A. (2009). Assessing the scale-specific importance of niches and other spatial processes on beta diversity: a case study from a temperate forest. Oecologia, 159, 377-388.

Lawton, J. (1999). Are there general laws in ecology? Oikos. 84, 177-192.

Legendre, P. (1993). Spatial autocorrelation: trouble or new paradigm? Ecology, 74, 1659-1673.

Legendre, P., Borcard, D. \& Peres-Neto, P.R. (2005). Analyzing beta diversity: Partitioning the spatial variation of community composition data. Ecological Monographs, 75, 435-450.

Legendre, P., Mi, X., Ren, H., Ma, K., Yu, M., Sun, I.-F., He F. (2009). Partitioning beta diversity in a subtropical broadleaved forest of China. Ecology. 90, 663-674.

Maraun, M., Martens, H., Migge, S., Theenhaus, A., Scheu, S. (2003). Adding to 'the enigma of soil animal diversity': fungal feeders and saprophagous soil invertebrates prefer similar food substrates. European Journal of Soil Biology, 39, 8595.

Martins da Silva, P., Berg, M.P., Serrano, A.R.M., Dubs, F., Sousa, J.P. (2012). Environmental factors at different spatial scales governing soil fauna community patterns in fragmented forests. Landscape Ecology, 27, 1337-1349.

McArdle, B.H., Anderson, M.J. (2004). Variance heterogeneity, transformations and models of species abundance: a cautionary tale. Can. J. Fish. Aquat. Sci., 61, 1294-1302.

Murphy, S.J., Audino, L.D., Whitacre, J., Eck, J.L., Wenzel, J.W., Queenborough, S.A., Comita, L.S. (2015). Species associations structured by environment and land-use history promote beta-diversity in a temperate forest. Ecology. 96(3), 705-715.

Pennisi, B.V., van lersel, M. (2002). 3 ways to measure medium EC. GMPro. 22(1), 46-48.

Rossi, J.P. (2003). Clusters in earthworm spatial distribution. Pedobiologia. 47(5-6), 490-496.

Rossi, J.-R., Lavelle, P., Tondoh, J.E. (1996). Statistical tool for soil biology. XI. Autocorrelogram and Mantel test, European. Journal of Soil Biology. 32, 195-203.

Saetre, P. (1999). Spatial patterns of ground vegetation, soil microbial biomass and activity in a mixed spruce-birch stand. Ecography, 22, 183-192.

Schneider, K., Migge, S., Norton, R.A., Scheu, S., Langel, R., Reineking, A., Maraun, M. (2004). Trophic niche differentiation in soil microarthropods (Oribatida, Acari): evidence from stable isotope ratios (N-15/N-14). Soil Biology and Biochemistry, 36, 1769-1774.

Schoener, T. W. (1974). Resource partitioning in ecological communities. Science, 185(4145), 27-39.

Siefert, A., C. Ravenscroft, M. D. Weiser, and N. G. Swenson. 2013. Functional beta-diversity patterns reveal deterministic community assembly processes in eastern North American trees. Global Ecology and Biogeography 6:682691.

Soinenen, J., Lennon, J.J. \& Hillebrand, H. (2007). A Multivariate Analysis of Beta Diversity across Organisms and Environments. Ecology, 88, 2830-2838.

Takeda, H. (1987). Dynamics and maintenance of Collembolan community structure in a forest soil system. Researches on Population Ecology, 29, 291-346.

Tarasov, V.V., (2012). Dnipropetrovsk and Zaporozhie regions flora. Second ed. Lira, Dnipropetrovsk (in Ukranian).

Tsatsenkin, I.A. (1970). Ecological evaluation of the fodder lands of the Carpathians and the Balkans on vegetation. Moscow, Institute of forages.

Vadunina, A. F., Korchagina, S. A. (1986). Methods for research of physical properties of the soil. Moscow, Agropromizdat.

Viketoft, M. (2013). Determinants of small-scale spatial patterns: importance of space, plants and abiotics for soil nematodes. Soil Biology and Biochemistry, 62, 92-98.

Wardle, D.A. (2006). The influence of biotic interactions on soil biodiversity. Ecology Letters, 9, 870-886.

Weslien, J., Djupström, L. B., Schroeder, M., Widenfalk, O. (2011). Long-term priority effects among insects and fungi colonizing decaying wood. Journal of Animal Ecology, 80, 1155-1162.

Whalen, J.K. (2004). Spatial and temporal distribution of earthworm patches in corn field, hayfield and forest systems of southwestern Quebec, Canada. Applied Soil Ecology, 27(2), 143-151.

Whittaker, R. H. (1960). Vegetation of the siskiyou mountains, Oregon and California. Ecological Monographs, 30, 279338.

Whittaker, R. H. (1972). Evolution and measurement of species diversity. Taxonomy, 21, 213-251.

Widenfalk, L. A., Bengtsson, J., Berggren, Å., Zwiggelaar, K., Spijkman, E., Huyer-Brugman, F., Berg, M.P. (2015). Spatially structured environmentalfiltering of collembolan traits in late successional salt marsh vegetation. Oecologia, 1-13.

Wilson, J.B., Habiba, G. (1995). Limitation to species coexistence: evidence for competition from field observations, using a patch model. Journal of Vegetation Science, 6., 369-376.

Zhukov, O.V. Gubanova, N.L. (2015). Diversity and dynamics of amphibians in floodplain ecosystems of the Samara river. Visnyk of Dnipropetrovsk University. Biology, ecology. 23(1), 66-73. doi:10.15421/011510 
Zhukov, A., Zadorozhnaya, G. (2016). Spatial heterogeneity of mechanical impedance of a typical chernozem: the ecological approach. Ekológia (Bratislava). 35, 263-278.

Zhukov, O.V., Kunah, O. M., Dubinina, Y.Y., Ganzha, D. S. (2017). Diversity and phytoindication ability of plant community. Ukrainian Journal of Ecology. 7(4), 14-31.

Zhukov, O.V., Kunah, O.N., Novikova, V.A. (2016). The functional organisation of the mesopedobionts community of sod pinewood soils on arena of the river Dnepr. Visnyk of Dnipropetrovsk University. Biology, ecology. 24(1), 26-39. doi:10.15421/011604

Zhukov, A.V., Kunah, O.N., Novikova, V.A., Ganzha, D.S. (2016). Phytoindication estimation of soil mesopedobionts communities catena and their ecomorphic organization. Biological Bulletin of Bogdan Chmelnitskiy Melitopol State Pedagogical University, 6 (3), 91-117 (in Russian). DOI: http://dx.doi.org/10.15421/201676

Zhukov, O.V., Kunah, O. M., Dubinina, Y.Y. (2017). Sensitivity and resistance of communities: evaluation on the example of the influence of edaphic, vegetation and spatial factors on soil macrofauna. Biosystems Diversity. 25(4), 328341. doi:10.15421/011750

Zhukov, O.V., Kunah, O. M., Dubinina, Y.Y., Ganzha, D. S. (2017). Diversity and phytoindication ability of plant community. Ukrainian Journal of Ecology. 7(4), 81-99.

\section{Citation:}

Dubinina, Y.Y. (2018). The spatial scaling of impact in edaphic and plant factors on the structuring of the soil macrofauna community. Acta Biologica Sibirica, 4 (3), 36-53.

Submitted: 18.02.2018. Accepted: 25.05.2018

cross ref $\mathrm{http}: / / \mathrm{dx}$. doi.org/10.14258/abs.v4i3.4366

(C) 2018 by the authors. Submitted for possible open access publication under the terms and conditions of the Creative Commons Attribution (CC BY) license (http://creativecommons.org/licenses/by/4.0/). 